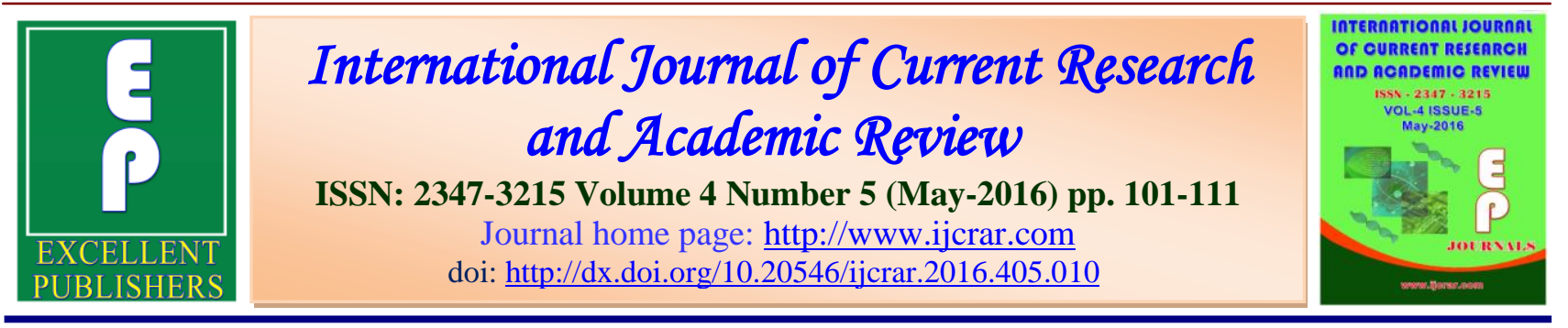

\title{
Juvenile Idiopathic Arthritis: Associated and Autoimmune Diseases with the Validity of Das 28
}

\author{
Ismail Ashraf Khalifa ${ }^{1 *}$, Hussein Koura ${ }^{2}$ and Abdelhameed Abdelfattah ${ }^{3}$ \\ ${ }^{1}$ Department of Rheumatology, Al- Azhar University, Egypt \\ ${ }^{2}$ Department of Pediatric, Al- Azhar University, Egypt \\ ${ }^{3}$ Department Clinical pathology - Al- Azhar University, Egypt
}

\begin{tabular}{|c|c|}
\hline KEYWORDS & A B S T R A C T \\
\hline $\begin{array}{l}\text { Juvenile } \\
\text { Ideopathic } \\
\text { Arthritis, } \\
\text { Autoimmune } \\
\text { thyroiditis, } \\
\text { Celiac disease, } \\
\text { DAS28, } \\
\text { validity. }\end{array}$ & $\begin{array}{l}\text { Juvenile idiopathic arthritis (JIA) is the most common chronic rheumatic } \\
\text { disease affecting children worldwide. Yet the association of JIA and } \\
\text { autoimmune diseases had not been studied extensively. This study aimed to } \\
\text { evaluate the validity of DAS28 score as screening tool for autoimmune } \\
\text { thyroid diseases and celiac disease associated with JIA. Ninety seven children } \\
\text { fulfilled the criteria for diagnosis of JIA according to classification criteria of } \\
\text { the International League of Association for Rheumatology (1)were recruited } \\
\text { in the study. Controls; } 97 \text { patients, were age and sex matched. Key } \\
\text { determinants of disease activity score } 28 \text { (DAS28) were examined. Thyroid } \\
\text { function tests (TSH, fT4 and fT3), serum total IgA, tissue transglutaminase } \\
\text { antibodies, thyroperoxidase antibodies, and thyroglobulin antibodies have } \\
\text { been studied. Fourteen cases (14.5\%) in JIA group were suffering from } \\
\text { autoimmune thyroiditis, two (2.1\%) of them had subclinical hypothyroidism, } \\
\text { while it was present only in } 1 \text { case (1\%)of the control group. Celiac disease } \\
\text { was associated with JIA in } 4 \text { cases }(4.1 \%) \text {. The sensitivity of DAS28 score } 6.1 \\
\text { or more for screening for autoimmune thyroiditis and celiac disease was } \\
89.5 \% \text { in case of oligoarthritis and } 88.8 \% \text { for polyarthritis. On the other hand } \\
\text { specificity was } 80.9 \% \text { for oligoarthritis and } 76.0 \% \text { for polyarthritis. The } \\
\text { negative predictive value was } 94.4 \% \text { for oligoarthritis and } 95 \% \text { for } \\
\text { polyarthritis. DAS28 score } 6.1 \text { or more is a valid tool for screening of } \\
\text { autoimmune thyroid diseases and celiac disease associated with JIA. A large } \\
\text { sample size study should be conducted to verify our results. }\end{array}$ \\
\hline
\end{tabular}

\section{Introduction}

Juvenile idiopathic arthritis (JIA) is a chronic and often disabling disease with variable outcome. It is the most common childhood rheumatological disease with an incidence of 1 in 1000 (Moncrieffe et al.,
2011). Up to $1 / 3$ of children are reported to have active disease progressing into adulthood (Carrasco et al., 2011). As patients with juvenile idiopathic arthritis (JIA) progress into adulthood, long-term 
outcome is determined by disease activity, physical and psychosocial development (Van Pelt et al., 2012).

The DAS28 is an index similar to the original DAS, consisting of a 28 tender joint count (range 0-28), a 28 swollen joint count (range 0-28), ESR, and an optional general health assessment on a visual analogue scale (range 0-100). Because of the use of reduced and non-graded joint counts, the DAS28 is easier to complete than the DAS. The DAS28 has a continuous scale ranging from 0 to 9.4 , and usually shows a Gaussian distribution in RA populations. The level of disease activity can be interpreted as low (DAS28 $\leq 3.2)$, moderate $(3.2>$ DAS28 $\leq$ 5.1 ), or high (DAS28 > 5.1). A DAS $28<2.6$ corresponds to being in remission according to the ARA criteria (Fransen et al., 2005).

The DAS28 (CRP) has been validated against radiographic progression and physical function. While the DAS28 (CRP) yielded a better EULAR response more often than the DAS28 (ESR), the validation profile was similar to the DAS28 (ESR), indicating that both measures are useful for assessing disease activity in patients with rheumatoid arthritis (Wells et al., 2009).DAS28 is used as a measure for activity score in JIA patients by Kostareva et al., 2011 (2011) and de Vries et al., 2011 (2011). The former found that, there is a strong correlation between DAS 28 and JIA patients at a high degree of activity while poor correlation holds at low degree activity. The latter examined the difference between JADAS 27 and DAS 28 in JIA, emphasizing that both of them are significantly used but giving more weight to JADAS27. consequently we have further investigated how reliable such a measure in JIA patients.

Autoimmune thyroid disease (AITD) is a term used to bring together a group of pathologies that has thyroid dysfunction and an autoimmune response against this endocrine organ as its hallmark (Eschler et al., 2011). It can be divided into those that cause hypothyroidism, hyperthyroidism or both. As organ specific autoantibody profile may be composed of 1) antibodies directed against the thyroperoxidase enzyme (TPOAb), 2) antibodies directed against thyroglobulin protein ( $\mathrm{TgAb})$ and 3 ) antibodies directed against thyrotropin receptor (TSHrAb). Hollowell et al., 2002 described a prevalence of $13 \%$ for TPOAb and $11.5 \%$ for $\mathrm{TgAb}$ among the general population. This prevalence rises in spontaneously hypothyroid patients (Carlé et al., 2006). In other words, AITD can be regarded as the most common autoimmune endocrine disease.It is important to note that there are no international criteria for the diagnosis of AITD. These cases were classified on the basis of an abnormal thyrotropin (TSH) test, or history of thyroid hormone therapy, and the presence of either TPOAb or TgAb (Cárdenas-Roldán et al., 2012).

Coeliac disease, an immune-mediated enteropathy that develops in susceptible individuals upon ingestion of gluten containing diet, is closely associated with other autoimmune endocrine disorders, particularly autoimmune thyroid disease. This disease has been found to be more prevalent in patients with autoimmune thyroid disease in general and especially in Hashimoto's thyroiditis than in the general population, ranging from $2 \%$ to $5 \%$. Conversely, there is also an increased prevalence of immune-based disorders among patients with Coeliac disease. The pathogenesis of co-existent autoimmune thyroid disease and Coeliac disease is not known, but these conditions share similar HLA haplotypes and are associated with the gene encoding cytotoxic T-lymphocyte- 
associated antigen-4. Hadithi et al., 2007 argued that, as, of 104 patients with Hashimoto's thyroiditis, sixteen (15\%) were positive for coeliac serology and five patients with documented villous atrophy were diagnosed with coeliac disease, while, of 184 patients with coeliac disease, 39 (21\%) were positive for thyroid serology (Hadithi et al., 2007).

An association of autoimmune diseases with RA and SLE was studied (Stagi et al., 2005). Yet the association of Juvenile idiopathic arthritis (JIA) and autoimmune diseases had not been studied as extensively as SLE and RA. To the best of my knowledge, no further studies highlighted a counter evidence till the time of writing this paper. To study an association between two diseases, a diagnostic accurate tool should be used.

The aim of this study, to evaluate the validity and feasibility of DAS28 score in screening for autoimmune thyroid diseases and celiac disease associated with JIA.

\section{Patients and Methods}

This study was carried out at Al-Hussein University Hospital. Ninety seven children fulfilling the criteria for diagnosis of juvenile idiopathic arthritis (JIA) according to classification criteria of the International League of Association for Rheumatology (ILAR)(1), were recruited in the study. They were known JIA patients and receiving their therapy according to treatment algorithm of Nistala et al., 2008.

Controls; 97 patients, were age and sex matched form the attendants to Al-Hussein University Hospital complaining of minor illness (e.g. common cold). At enrollment caretakers provided informed consents and the following data were collected: age, gender, duration of JIA, treatment and hospital admission. After that a thorough clinical examination was performed and nutritional status was assessed by using CDC chart.

The following key determinants of disease activity score 28 (DAS28) were examined: numbers of tender, swollen joints, and patient general health scores by visual analogue scale (VAS). Then the following investigations were performed for all enrolled patients: Acute phase reactants (ESR), C-reactive protein (CRP),Serum rheumatoid factor(RF) (ILAR categorized the JIA polyarticular arthritis to rheumatoid factor positive and negative): by turbidimetry for quantitative determination (Winkles et al., 1989), serum total IgA, tissue transglutaminase antibodies (tTgAbs), thyroperoxidase antibodies (TPOAbs), thyroglobulin antibodies(TgAbs), thyroidstimulating hormone(TSH), free thyroxin (fT4), free triiodothyronine (fT3).

Serum was divided into aliquots and they were stored at -20C till timeof analysis. Determination of TSH(normal range 0.7-6.4 $\mathrm{mIU} / \mathrm{l}$ ),fT3 (normal range 230-660 pg/dl) and fT4(normal range $0.8-2.3 \mathrm{ng} / \mathrm{dl}$ ) were done by automated chemiluminscence immunoassay technique (Immulite autoanalyser). Thyroid antibodies were measured using ELISA technique (IMMCO diagnostics, USA).

The cut off point for positivity of TPOAbs was $>20 \mathrm{IU} / \mathrm{ml}$ while it was $>80 \mathrm{IU} / \mathrm{ml}$ for TgAbs. Serum total IgA concentration was determined by immuno turbidmetric technique using a Roche / Hitaschi analyzer with Roche Tina-quant reagents and values below $33 \mathrm{mg} / \mathrm{dl}$ were regarded as $\operatorname{IgA}$ deficiency. Patients with $\operatorname{IgA}$ deficiency were excluded from the study; it can make the celiac tests give a false negative. ELISA (IMMCO diagnostics, USA) kit was used for estimation of $\mathrm{tTgAbs}(\operatorname{IgA})$ and the cut 
off point for positivity was > 20 Units. All ELISA techniques were done in duplicate.

Subclinical hypothyroidism was defined as TSH level >6.4 mIU/l together with normal serum thyroid hormone levels. Overt hypothyroidism was defined as raised TSH together with a decreased serum thyroid hormone level. Diagnosis of autoimmune thyroiditis was considered with elevated TPOAbs and/or TgAbs values. Patients having +ve tTgAbs were diagnosed as coeliac disease if they responded well to feeding with gluten free diet (GFD)(22). Autoimmune diseases defined as autoimmune thyroiditis and celiac disease.

\section{Statistical Methods}

Data entry and analysis were performed by using the statistical package Epi Info v 6.04. Sensitivity, specificity and positive and negative predictive values of DAS28 score with a $95 \%$ confidence interval (CI) were calculated. Chi squared and t-test were used for the difference between proportions and two means respectively. A five percentage $(5 \%)$ significance level was considered.

\section{Results and Discussion}

Ninety seven patients suffering from JIA were recruited in the study. They were classified according to ILAR into 61 (7 RF +ve) with oligoarthritis, 34 with (19 RF +ve) polyarthritis and 2 cases suffering from systemic onset form. As the sample of our study is randomly collected, children withenthesitis related arthritis and juvenile psoriatic arthritis were not captured, not excluded. The mean age among JIA patients was $10.6 \pm 1.1$ years versus $10.3 \pm 1.2$ years among control group. Twenty one subjects $(21.6 \%)$ were males in each group. DAS28 was $5.5 \pm 2.1,5.3 \pm 1.0$ and $5.5 \pm 2.1$ among oligoarthritis, polyarthritis and systemic onset forms respectively (table 1).
Fourteen cases $(14.5 \%)$ in JIA group were suffering from autoimmune thyroiditis, two $(2.1 \%)$ of them had subclinical hypothyroidism (table2). In the control group, autoimmune thyroiditis was present only in 1 (1\%) case (table2) and the difference between the JIA group and control was highly statistically significant $(\mathrm{p}=0.001$, table2). Among cases with autoimmune thyroiditis in JIA group were positive for TgAbs and TPOAbs together (five cases), TPOAbs (five cases), and TgAbs (four cases). On other hand the only case with autoimmune thyroiditis in the control group was positive for TPOAbs (table4). The rareity of subclinical hypothyroidism and celiac disease among JIA children reflected insignificant results is the main reason for the insignificant results. This can be remedied in a wider scale study.

Subclinical hypothyroidism alone, was present in ten cases (10.3\%) among JIA group with a mean of TSH $10.8 \pm 0.4 \mathrm{mIU} / \mathrm{l}$ while, it was present in two cases $(2.1 \%)$ in

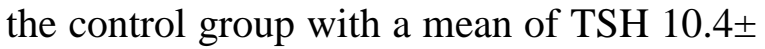
$0.2 \mathrm{mIU} / \mathrm{l}$ and the difference between two groups was statistically significant $(\mathrm{p}=0.01$, table2). Celiac disease was associated with JIA in $4(4.1 \%)$ cases who complained from recurrent diarrhea that responded well to feeding with gluten free diet and none of the control group suffers from it (table 2).

The mean DAS28 for patients with autoimmune diseases; autoimmune thyroiditis and celiac disease, in oligoarthritis group was $6.2 \pm 0.9$ versus $5.4 \pm 0.8$ among those without and the difference between the two groups was statistically highly significant $(\mathrm{p}=0.001$, table5). On the other hand it was $6.1 \pm 0.9$ in polyarthritis with autoimmune diseases versus $5.3 \pm 0.6$ among those without and the difference between two groups was a 
statistically highly significant $(\mathrm{p}=0.002$, table5).

The sensitivity test of DAS28 showed that at 6.1 or more autoimmune thyroiditis and celiac disease scored $89.5 \%$ in oligo arthritis and $88.8 \%$ in polyarthritis. On the other hand the specificity test was $80.9 \%$ in oligoarthritis and $76.0 \%$ in polyarthritis. The negative predictive value was $94.4 \%$ in oligoarthritis and $95 \%$ in polyarthritis (table6).

Pain is a difficult symptom to measure because it fluctuates and may be experienced or described differently by different people at different times (McWilliams et al., 2012). DAS28, among other tests, is an affective measure in RA activity. To extend the scope of DAS28 effectiveness in measuring disease activity we have chosen it as a measurable score in JIA. The results of DAS28 in our study scoring $5.5 \pm 1.6$ among oligoarthritis, polyarthritis and systemic onset forms together show a high level of activity. Some argue that DAS28 is not a valid measure for children. However, in the first place, Kostareva et al., 2011 and de Vries et al., 2011 proved its validity as mentioned earlier. Secondly, DAS28 implies the probability of joints affection; this could entail any number of joints, not necessarily all or none. Thirdly, during the remission DAS 28 can be estimated even with a few joints or none. To examine the effectiveness of DAS28 for patients with autoimmune diseases; autoimmune thyroiditis and celiac disease, in oligoarthritis group we calculated the mean value. Oligoarthritis patients affected by the previous diseases scores 6.2 \pm 0.9 versus $5.4 \pm 0.8$ non-affected patients and the difference between the two groups was statistically highly significant $(\mathrm{p}=0.001)$. On the other hand the score was $6.1 \pm 0.9$ in polyarthritis patients affected with autoimmune diseases versus $5.3 \pm 0.6$ non-affected patients and the difference between the two groups was also statistically highly significant $(\mathrm{p}=0.002)$. Having used DAS28 as sensitivity and specificity tests for screening autoimmune thyroid and celiac diseases, it turned out that DAS28 scores 6.1 or more, emphasizing its validity as a tool in investigating such diseases. The sensitivity score was $89.5 \%$ and $88.8 \%$ for oligoarthritis and polyarthritis respectively. On the other hand the specificity test scores $80.9 \%$ and $76.0 \%$ for oligoarthritis and polyarthritis respectively. Likewise, the relative risk of autoimmune thyroid diseases was $14.5 \%$ and $4.1 \%$ for celiac disease. Therefore, the significant results of DAS28 in sensitivity and specificity tests may extend the scope of DAS28 beyond its common application. Therefore, we brought it to the attention of the reader early in our discussion.

Our results were higher than $(4.41 \pm 1.21)$ calculated by Ringold et al., 2010, who stated that DAS28 tended to have a higher operating characteristic curve area under the curve (AUC) for the ACR pediatric measures than did the DAS, Simplified Disease Activity Index (SDAI) and Clinical Disease Activity Index (CDAI), in spite of that they used the JADAS (20, 27 and 71) as a preferable measure but in a small number in comparison to our study, while their results support the convergent validity of the continuous measures of disease activity used in RA (the DAS, DAS28, SDAI, and CDAI) and the JADAS for the ACR pediatric measures of relative response, flare, and inactive disease in polyarticular course JIA. However, our study was contradictory to the study of Kostareva et al., 2011 who found that DAS28 is not applicable in all forms of JIA and has poor correlation with only form JADAS 71 in low activity after examining 1099 patients with JIA. Yetde Vries et al., 2011, found that The JADAS-27 correlated 
moderately with DAS28 ( $\mathrm{R}=0.63)$. Furthermore, Van Pelt et al., 2012 stated that the advantages of JADAS 27 may surpass DAS 28 because it includes measures for the cervical spine, hips and ankles, joints which are often affected in (adult) patients with JIA as shown in the study of Sixty-three patients with JIA (aged 10-27 years), with a different mean age than our study $(10.6 \pm 1.1)$.

Associated autoimmune diseases, such as thyroid and coeliac diseases, have been extensively addressed before, mainly in adult rheumatoid arthritis, whilst the series of JIA are under-researched. We can notice an overlap between JIA and ATDs as a part of systemic autoimmune diseases; they share genetic susceptibility, imune dysfunction and environmental factor. This could highlight the reason of association. In addition, the pathogenesis of co-existent autoimmune thyroid disease and Coeliac disease is not known, but these conditions share similar HLA haplotypes and are associated with the gene encoding cytotoxic T-lymphocyte-associated antigen-4Biro et al., 2006 evaluated the prevalence of systemic autoimmune diseases in patients with autoimmune thyroid disease (ATD) stressing the paucity of relevant literature . In their study, $8.2 \%$ out of 1,517 patients were diagnosed with systemic lupus erythematosus (SLE), rheumatoid arthritis (RA), systemic sclerosis (SSc), mixed connective tissue disease (MCTD), Sjögren's syndrome (SS) and polymyositis/ dermatomyositis (PM/DM); the majority of patients have been with positive tests for Hashimoto's disease (24\%) while those with Graves' disease were (10\%). This may reflect how low ATDs diseases among systemic autoimmune diseases

In our study 14 cases $(14.5 \%)$ in JIA group suffered from autoimmune thyroiditis, two $(2.1 \%)$ of them had subclinical hypothyroidism. Mihailova et al., 1999 previously reported that among 27 JIA children, $44.4 \%$ had autoimmune thyroiditis; of these patients $85.2 \%$ were euthyroid, and $11.1 \%$ had a subclinical hypothyroidism. In line with our study, Alpigiani et al., 2002, examining 66 JIA patients, showed just nine (14\%) patients with antithyroid antibodies and all children showed a normal thyroid function.

We observed a significant increased prevalence of subclinical hypothyroidism $(\mathrm{P}<0.01)$, autoimmune thyroiditis $(\mathrm{P}<0.001)$ and celiac disease $(\mathrm{P}<0.05)$, in JIA patients, compared with the control group in agreement with Harel et al., 2006, Stagi et al., 2005 and Abd, 2011.

The data reported by many authors vary markedly due to differences in research methods and sample size. Our results were higher than that of Harel et al., 2006 who stated that, in a small group of children with juvenile idiopathic arthritis (JIA) (66) compared to controls (89) the occurrence of antithyroid antibodies [antithyroglobulin $(11.3 \%)$ and antithyroid peroxidase (7.9\%)] as well as thyroid function were higher in the study group than in controls $(2.6+/-2.3$ vs $1.9+/-1.0 \mathrm{mIU} / \mathrm{l} ; \mathrm{p}=0.01)$. Also, our results are considered higher than that of Stagi et al., 2005 who stated that fourteen (9.3\%) patients showed subclinical hypothyroidism, 17 (11.9\%) patients showed autoimmune thyroiditis with nine patients also showing a non-homogeneous thyroid parenchyma at ultrasound evaluation, compared with controls, additionally JIA patients had higher prevalence of subclinical hypothyroidism $\quad(\mathrm{P}<0.01), \quad$ autoimmune thyroiditis $(\mathrm{P}<0.0001)$. Moreover Abd, 2011 detected the autoimmune thyroiditis in 9 $(11.8 \%)$ patients (median age $9.2 \mathrm{yr}$, range 2.0-15.9 yr), of these, 6 patients were found positive for $\mathrm{TgA}$. 
In the present study, the positivity for autoantibodies among $\operatorname{JIA}(\mathrm{n}=97)$ was TgAbs in 4 patients $(4.1 \%)$, TPOAbs in 5 patients $(5.2 \%)$ with one $(1 \%)$ in control group, in both (TgAbs and TPOAbs) in 5 patients $(5.2 \%)$ and (TgAbs and/or TPOAbs) in 14 patients (14.5\%), while the tTgAbs was found in 4 patients $(4.1 \%)$.

The majority (12/14) of children with subclinical hypothyroidism reported in our study did not show findings suggestive of autoimmune thyroiditis, this result is contradictory to Mihailova et al., 1999 and in line with Stagi et al., 2005 and might suggest that thyroid function in JIA could also be impaired in children without an associated autoimmune thyroiditis. Also, it is in conformity with Abd, 2011who found 7 (9.3\%) JRA patients showing sub clinical hypothyroidism with one of these presented autoimmune thyroiditis.

Table.1 Clinical and laboratories characters of JIA patients (mean \pm SD):

\begin{tabular}{|l|c|c|c|}
\hline & $\begin{array}{c}\text { Oligoarthritis } \\
\mathrm{n}=61\end{array}$ & $\begin{array}{c}\text { Polyarthritis } \\
\mathrm{n}=34\end{array}$ & Systemic $\mathrm{n}=2$ \\
\hline Swollen joints & $1.3 \pm 1.3$ & $12.1 \pm 5.2$ & $2.5 \pm 0.5$ \\
Tender joints & $1.3 \pm 1.2$ & $21.0 \pm 6.8$ & $2.5 \pm 0.5$ \\
Acute phase reactants (ESR) & $23.5 \pm 14.4$ & $21.8 \pm 11.3$ & $49.8 \pm 13.4$ \\
C-reactive protein (CRP) & $16.7 \pm 14.4$ & $13.4 \pm 15.3$ & $20.7 \pm 4.9$ \\
VAS patient general health & $7.1 \pm 1.6$ & $6.2 \pm 1.2$ & $6.8 \pm 0.8$ \\
Total index of DAS28 & $5.5 \pm 2.1$ & $5.3 \pm 1.0$ & $5.5 \pm 0.2$ \\
\hline
\end{tabular}

Table.2 Relative risk of thyroid and celiac diseases in JIA and Control groups $(n=194)$ :

\begin{tabular}{|c|c|c|c|c|c|c|}
\hline & \multicolumn{2}{|c|}{ JIA groupn $=97$} & \multicolumn{2}{|c|}{ Control groupn $=97$} & \multirow[t]{2}{*}{$\mathrm{RR}^{*}$} & \multirow[t]{2}{*}{$\mathrm{P}$} \\
\hline & $\mathrm{No}$ & $\%$ & No & $\%$ & & \\
\hline Subclinical hypothyroidism & 10 & 10.3 & 22.1 & & 5 & 0.01 \\
\hline Autoimmune thyroiditis & 12 & 12.4 & 11.0 & & 9.5 & 0.001 \\
\hline Subclinical hypothyroidism \& & & & & - & & \\
\hline autoimmune thyroiditis & 2 & 2.1 & - & - & - & NS \\
\hline Celiac disease & 4 & 4.1 & & & - & NS \\
\hline
\end{tabular}

* RR = Relative Risk

Table.3 Thyroid and celiac diseases in JIA subtype ( $n=97)$ :

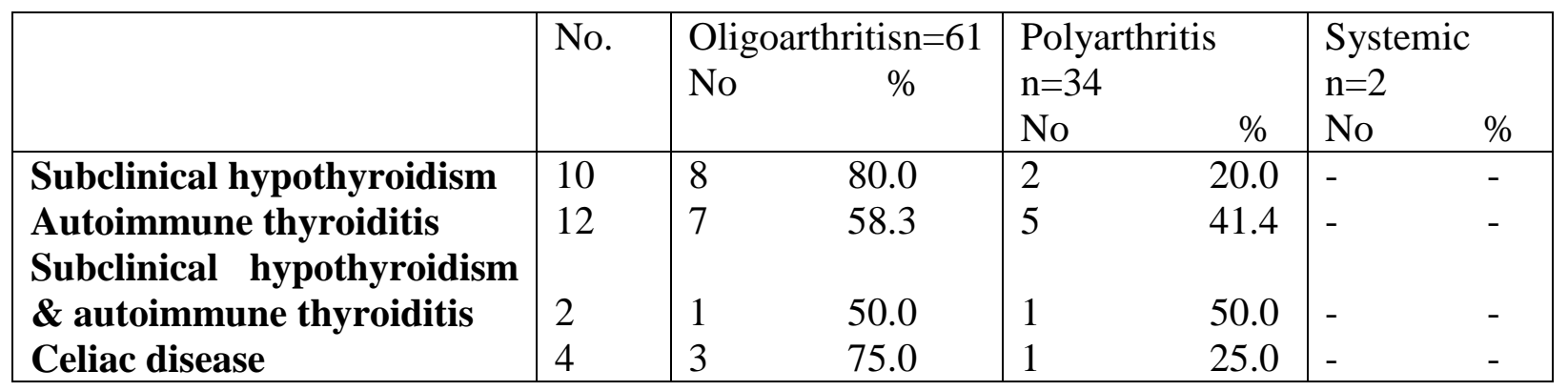


Table.4 Positivity for autoantibodies among JIA and Control groups ( $\mathrm{n}=194)$ :

\begin{tabular}{|l|cc|lc|l|}
\hline & \multicolumn{2}{|l|}{ JIA group $n=97$} & \multicolumn{2}{|l|}{ Control group n=97 } & P \\
& No. & $\%$ & No. & $\%$ & \\
\hline TgAbs and/or TPOAbs & 14 & 14.5 & 1 & 1 & 0.0005 \\
TgAbs+ TPOAbs & 5 & 5.2 & - & - & \\
TgAbs & 4 & 4.1 & - & - & \\
TPOAbs & 5 & 5.2 & 1 & 1 & \\
tTgAbs & 4 & 4.1 & - & - & \\
TSH & 10 & 10.3 & 2 & 2.1 & \\
\hline
\end{tabular}

Table.5 DAS 28 and autoimmune diseases associated with JIA (mean \pm SD) (n=95)

\begin{tabular}{|l|c|c|c|l|}
\hline & No. & $\begin{array}{l}\text { DAS28 of patients with JIA and } \\
\text { autoimmune diseases }\end{array}$ & $\begin{array}{l}\text { DAS28 of patients with JIA } \\
\text { only }\end{array}$ & P \\
\hline Oligoarthritis & 61 & $(\mathrm{n}=11) 6.2 \pm 0.9$ & $(\mathrm{n}=50) 5.4 \pm 0.8$ & 0.001 \\
\hline Polyarthritis & 34 & $(\mathrm{n}=7) 6.1 \pm 0.7$ & $(\mathrm{n}=27) 5.3 \pm 0.6$ & 0.002 \\
\hline
\end{tabular}

In our study, in alignment with Robazzi et al., 2013, oligoarticular JIA patients seem more frequently to develop subclinical hypothyroidism in comparison with those with polyarticular and systemic onset. However, Koga et al., 2001 stated thatthe oligoarticular JIA has not been reported to be associated with hashimoto thyroiditis.

Our study showed that the children positive for antibodies are 14 oligoarticular, 6 polyarticular and no systemic onset form, while Harel et al., 2000 demonstrated that the children positive for antibodies all had oligoarticular JIA.

In our study Celiac disease was associated with JIA in four cases $(4.1 \%)$, three of them were oligoarticular and one polyarticular with no systemic onset form. This shows that celiac disease has low rate in general. It is even lower than than that found by the study of Stagi et al., 2005, who demonstrated ten $(6.6 \%)$ patients, in spite of higher prevalence of coeliac disease $(P<0.005)$ in JIA patients compared with controls in both of their and our studies. Our study confirms and supports data from a previous study of Lepore et al., 1996 George et al., $1996 \mathrm{Abd}, 2011$ and Nuñez et al., 2011 who, documented that, the prevalence of coeliac disease in patients with JIA appeared to be higher than in controls. On the contrary, Al-Mayof et al., 2003 showed that $77.8 \%$ of JIA patients had anti gliadine IgA $\mathrm{Ab}$ and $22.2 \%$ of JRA patients had anti gliadine IgGAb. No association in our results between autoimmune thyroiditis and coeliac disease was spotted, unlike Abd 2011 who showed an association.

Finally, JIA children particularly girls have an increased prevalence of autoimmune thyroiditis, subclinical hypothyroidism and coeliac disease. These data seem to suggest careful monitoring of thyroid function, thyroid autoantibodies and coeliac disease in JIA children.

\section{Conclusion}

In conclusion, overlapping of autoimmune diseases was frequently demonstrated. JIA patients should be continuously followed up and once new clinical symptoms develop, appropriately evaluated for thyroid diseases. 
Amongst JIA patients, girls and oligoarticular subtype are particularly predisposed to autoimmune thyroid diseases. DAS 28 can be used as a measure of disease activity in JIA and also can give an indicator for autoimmune disease predisposition. DAS28 score 6.1 or more is a valid tool for screening of autoimmune thyroid diseases and celiac disease associated with JIA. A large sample size study should be conducted to verify our results.

\section{Competing Interests}

The authors declare that they have no competing interests.

\section{References}

Abd, W.S. 2011. Thyroid Function, Autoimmune Thyroiditis and Celiacin Juvenile Rheumatoid Arthritis Patients; Iraqi J. Sci., Vol.52, No.4, 2011, PP.531-535.

Al-Mayof, S., Al-Mehaidib, A., Alkaff, M. 2003. The significance of celiac disease in children with juvenile rheumatoid arthritis; Saudi J., 9: 7580 .

Alpigiani, M.G., Cerboni, M., Bertini, I., d'Annunzio, G., Haupt, R., Iester, A, et al., 2002. Endocrine autoimmunity in young patients with juvenile chronic arthritis. Clin. Exp. Rheumatol., 20: 565-8.

Biro, E., Szekanecz, Z., Czirjak, L., Danko, L., Kiss, E., Szabo, N.A., et al., 2006. Association of systemic and thyroid autoimmune diseases. Clin. Rheumatol., 25: 240-5.

Cárdenas-Roldán, J., Amaya-Amaya, J., Hoz, J.C., Giraldo-Villamil, J., Montoya-Ortiz, G., Cruz-Tapias, P., et al., 2012. Autoimmune thyroid disease in rheumatoid arthritis: A global perspective; Arthritis, 864907.
Carlé, A., Laurberg, P., Knudsen, N., Perrild, H., Ovesen, L., Rasmussen, L.B., et al., 2006. Thyroid peroxidase and thyroglobulin auto-antibodies in patients with newly diagnosed overt hypothyroidism, Autoimmunity, 39: 497-503.

Carrasco, R., Cobb, J., Baildam, E., Foster, H., Gardner-Medwin, J., Chieng, A., et al. 2011. Predictors of disability in children with inflammatory arthritis, two and three years after first presentation to paediatric rheumatology. Results from the childhood arthritis prospective study (CAPS); Pediatric. Rheumatol.,, 9(Suppl 1):O42.

Ch'ng, C.L., Jones, M.K., Kingham, J.G. 2007. Celiac disease and autoimmune thyroid disease. Clin. Med. Res., 5(3): 184-92.

Collin, P., Kaukinen, K., Valimaki, M., Salmi, J. 2002. Endocrinological disorders and celiac disease. Endocr. Rev., 23: 464-483.

De Vries, L.D., Heijstek, M.W., Groot, N., Bulatović, M., Wulffaat, N.M. 2011. Validation of the juvenile artritis disease activity score in 1124 patient visits; Pediatric Rheumatol.,, 9(Suppl 1): P154.

Eschler, D.C., Hasham, A., Tomer, Y. 2011. The etiology of autoimmune thyroid diseases, Clin. Rev. Allergy \& Immunol., 41: 190-7.

Fransen, J., van Riel, P.L.C.M. 2005. The Disease Activity Score and the EULAR response criteria. Clin Exp. Rheumatol., 23(39): S93-S99.

George, E., Hertzberger, T., Van SuijlekomSmit, L. 1996. Juvenile chronic arthritis and coeliac disease in The Netherlands. Clin. Exp. Rheumatol., 14: 571- 575.

Hadithi, M., de Boer, H., Meijer, J.W.R., Willekens, F., Kerckhaert, J.A., 
Heijmans, R., et al., 2007. Coeliac disease in Dutch patients with Hashimoto's thyroiditis and vice versa. World J Gastroenterol (2007); 13(11): 1715-1722.

Harel, L., Prais, D., Uziel, Y., Mukamel, M., Hashkes, P., Harel, G., et al., 2006. Increased prevalence of antithyroid antibodies and subclinical hypothyroidism in children with juvenile idiopathic arthritis. $J$. Rheumatol., 33: 164-164.

Hollowell, J.G., Staehling, N.W., Flanders, W.D., Hannon, W.H., Gunter, E.W., Spencer, C.A, et al., 1988. Serum TSH, T(4), and thyroid antibodies in the United States population (1988 to 1994): National Health and Nutrition Examination Survey (NHANES III), The Journal of Clinical Endocrinology and Metabolism, 87: 489-99.

Koga, Y., Kuromaru, R., Takada, H., Hara, T. 2001. Juvenile idiopathic arthritis associated withautoimmune thyroid disorders and autoimmune cholangitis; Rheumatol., 40: 942-943.

Kostareva, O.M., Nikishina, I.P., Erdes, S.F., Salugina, S.O. 2011. Evaluation of disease activity in a population of Russian JIA patients; Pediatric Rheumatol., 9(Suppl 1): P209.

Lepore, L., Martelossi, S., Pennesi, M., Falcini, F., Ermini, M.L., Ferrari, R., et al., 1996. Prevalence of celiac disease in patients with juvenile chronic arthritis. J. Pediatr., 129: 311-13.

McWilliams, D.F., Zhang, W., Mansell, J.S., Kiely, P.D., Young, A., Walsh, D.A. 2012. Predictors of Change in Bodily Pain in Early Rheumatoid Arthritis: An Inception Cohort Study; Arthritis Care \& Res., Vol. 64, No. 10, pp 1505-1513.
Mihailova, D., Grigorova, R., Vassileva, B., Mladenova, G., Ivanova, N., Stephanov, S., Lissitchky, K., Dimova, E. 1999. Autoimmune thyroid disorders in juvenile chronic arthritis and systemic lupus erythematosus. Adv. Exp. Med. Biol., 455: 55-60.

Moncrieffe, H., Holzinger, D., Ursu, S., Patrick, F,. Kassoumeri, L., Roth, J., Wedderburn, L.R. 2011. Can inflammatory markers predict response to methotrexate in JIA? Results from the CHARM study; Pediatric. Rheumatol., 9(Suppl 1):O10

Nistala, K., Woo, P., Wedderburn, L.R. 2008. Juvenile Idiopathic Arthritis; Firestein: Kelley's Textbook of Rheumatology (2008), 8th ed. Copyright (C) 2008 W. B. Saunders Company.

Nuñez, E., Galindo, R., Lopez, E., Diaz, G., Vicioso, I.M. 2011. Coeliac disease and intestinal inflammation in juvenil idiopathic arthritis; Spain Pediatric. Rheumatol., 9(Suppl 1): P168.

Ogden, C.L., Kuczmarski, R.J., Flegal, K.M., Mei, Z., Guo, S., Wei, R., et al., 2000. Centers for Disease Control and Prevention 2000 Growth Charts for the United States: Improvements to the 1977 National Center for Health Statistics Version; Pediatrics, 109: 45-60.

Petty, R.E., Southwood, T.R., Manners, P., Baum, J., Glass, D.N., Goldenberg, J., et al., 2001. International League of Associations for Rheumatology classification of juvenile idiopathic arthritis: Second revision, Edmonton, 2001. J. Rheumatol., 31: 390-392.

Ringold, S., Bittner, R., Neogi, T., Wallace, C.A., Singer, N.G. Performance of Rheumatoid Arthritis Disease Activity Measures and Juvenile 
Int.J.Curr.Res.Aca.Rev.2016; 4(5): 101-111

Arthritis Disease Activity Scores in Polyarticular-Course Juvenile Idiopathic Arthritis: Analysis of Their Ability to Classify the American College of Rheumatology Pediatric Measures of Response and the Preliminary Criteria for Flare and Inactive Disease; Arthritis Care \& Res., Vol. 62, No. 8, pp 1095-1102. Robazzi, T.C., Adan, L..F, Pimentel, K., Guimarães, I., Magalhães, Filho, J., Toralles, M.B., Rolim, A.M. 2013. Autoimmune endocrine disorders and coeliac disease in children and adolescents with juvenile idiopathic arthritis and rheumatic fever. Clin. Exp. Rheumatol., 31(2): 310-7. Epub 2013 Feb 7.

See, J., Murray, J.A. 2006. Gluten-Free Diet: The Medical and Nutrition Management of Celiac Disease; Nutr. Clin. Pract., vol. 21 no. 1 1-15.

Shin, J.I., Kim, M.J., Lee, J.S. 2009. Graves' disease, rheumatoid arthritis, and anti-tumor necrosis factor-alpha therapy, J. Rheumatol., 36: 449-50.

Stagi, S., Giani, T., Simonini, G., Falcini, F. 2005. Thyroid function, autoimmune thyroiditis and coeliac disease in juvenile idiopathic arthritis;

Rheumatol., 44: 517-520.

Van Pelt, P.A., Takken, T.T., van Brussel, M., de Witte, M., Kruize, A.A., Wulffraat, N.M. 2012. Aerobic capacity and disease activity in children, adolescents and young adults with juvenile idiopathic arthritis (JIA); Pediatric Rheumatol., 10: 25.

Wells, G., Becker, J.C., Teng, J., Dougados, M., Schiff, M., Smolen, J., Aletaha, D., van Riel, P.L.C.M. 2009. Validation of the 28-joint Disease Activity Score (DAS28) and European League Against Rheumatism response criteria based on C-reactive protein against disease progression in patients with rheumatoid arthritis, and comparison with the DAS28 based on erythrocyte sedimentation rate; Ann. Rheum. Dis., 68(6): 954-960.

Winkles, J.W., Lunec, J., Gray, L. 1989. Automated enhanced latex agglutination assay for RF in serum. Clin. Chem., 35: 303-307.

\section{How to cite this article:}

Ismail Ashraf Khalifa, Hussein Koura and Abdelhameed Abdelfattah. 2016. Juvenile Idiopathic Arthritis: Associated and Autoimmune Diseases with the Validity of Das 28. Int.J.Curr.Res.Aca.Rev.4(5): 101-111. doi: http://dx.doi.org/10.20546/ijcrar.2016.405.010 